\title{
Preventing the birth of infants with Down's syndrome: a cost-benefit analysis
}

\author{
SPENCER HAGARD， FELICITY A CARTER
}

British Medical fournal, 1976, 1, 753-756

\begin{abstract}
Summary
The costs and economic benefits of providing routine prenatal diagnosis of Down's syndrome with termination of affected pregnancies in older pregnant women in the west of Scotland were examined. The potential economic benefits would be greater than the costs for women aged 40 and over, probably about equal to costs for those aged 35 and over, but less than costs if the service were extended to women under 35.
\end{abstract}

\section{Introduction}

Down's syndrome accounts for between a quarter and a third of all moderate and severe mental handicap (intelligence quotient (IQ) $<55)$ in children of school age. ${ }^{12}$ Its birth prevalence is currently being slightly reduced by providing prenatal diagnosis and selective abortion to older pregnant women on request. To make a major impact on the problem, however, would require mass prenatal diagnostic programmes directed, in the first instance, towards all older pregnant women-that is, those at higher risk. We consider here the relation between the likely costs and economic benefits of establishing such a programme in the west of Scotland. In evaluating the economic benefits resulting

University Departments of Community Medicine and Medical Genetics, Glasgow G20 9NB

SPENCER HAGARD, MB, DPH, employee of Greater Glasgow Health Board on secondment to University of Glasgow

Health Services Operational Research Unit, University of Strathclyde, Glasgow G4 0NG

FELICITY A CARTER, MSc, research fellow from terminating pregnancies affected with Down's syndrome we considered two situations, one in which women do not become pregnant again after termination (no replacement), and the other in which termination is followed by a further pregnancy (replacement). The outcome of replacement pregnancies is assumed to be normal. Since a programme testing for Down's syndrome could also diagnose fetal myelocele, the costs and economic benefits of this are also taken into account.

\section{Method}

For the population living in the area covered by the six west of Scotland health boards and served by the Genetic Advisory Centre in Glasgow, we estimated for 1975-94 for Down's syndrome: $(a)$ the number of births by five-year maternal age groups; $(b)$ the survival rates and degree of handicap of survivors; $(c)$ the costs to society of caring for survivors; $(d)$ the characteristics, including number of affected births prevented, of a prenatal diagnostic programme; and (e) the costs of running such a programme.

The savings in resources made by preventing affected births, in both replacement and no replacement circumstances, were calculated. The costs and economic benefits of testing all specimens for fetal myelocele were also considered.

All costs were standardised to a value for July 1974, using the Retail Price Index, ${ }^{3}$ and future costs were discounted at $10 \%$, the rate currently used by the UK Treasury, to obtain the net present values. The variations of costs with benefits under different conditions were examined.

\section{Results}

EPIDEMIOLOGY AND NATURAL HISTORY

Differences in methods of ascertainment probably account for much of the reported variation in the rates of prevalence of Down's syndrome: the more exhaustive the case finding the higher the rate recorded. The highest rates yet recorded in a European population ${ }^{4}$ (table I) were applied to west of Scotland 20-year birth projections, derived from 
TABLE I-Live birth prevalence of Down's syndrome by five-year maternal age groups (after Lindsjö ${ }^{4}$ )

\begin{tabular}{c|c|c|c|c|c|c|c}
\hline $\begin{array}{c}\text { Maternal age (years): } \\
\text { Birth prevalence, 1 in: }\end{array}$ & $<19$ & $20-24$ & -29 & -34 & -39 & -44 & $\geqslant 45$ \\
\hline
\end{tabular}

population and age-specific fertility predictions. ${ }^{56}$ This gave estimates of the number of births of infants with Down's syndrome in each five-year age group of women in each of the years 1975-94. We calculated that total births to women over 40 would vary a little about a mean of 550 a year while to women aged 35-39 the number would vary between 1780 and 2340 a year. Over the 20 years an average of $5.4 \%$ of all births but $29 \%$ of births of infants with Down's syndrome would be to women aged 35 and over; $1 \cdot 1 \%$ of all births but $16 \%$ of births of infants with Down's syndrome would be to women aged 40 and over.

Survival-An increasing proportion of infants with Down's syndrome survive. ${ }^{7}$ Estimates of likely survival to various ages were calculated from the results of two comprehensive surveys ${ }^{8}{ }^{9}$ and are shown in tables II and III.

Mental handicap-Using data collected in north-east Scotland ${ }^{10}$ we estimated that $20 \%$ of children with Down's syndrome would have an IQ in the range $50-69,75 \%$ in the range $20-49$, and the rest below 20.

TABLE II-Estimated proportion of cohort of 100 people with Down's syndrome surviving at various ages

$$
\begin{array}{l|r|r|r|r|r|r|r|r|r|r|r|r|r|r|r|r}
\text { Age (years): } & 1 & 2 & 3 & 4 & 5 & 10 & 15 & 20 & 25 & 30 & 35 & 40 & 45 & 50 & 60 & 70 \\
\hline
\end{array}
$$

\begin{tabular}{c|c|c|c|c|c|c|c|c|c|c|c|c|c|c|c|c|}
$\begin{array}{c}\text { Age (years): } \\
\text { No of survivors: }\end{array}$ & 76 & 73 & 71 & $\mathbf{4}$ & $\mathbf{5}$ & $\mathbf{1 0}$ & $\mathbf{1 5}$ & 20 & 25 & 30 & 35 & 40 & 45 & 50 & 60 & 70 \\
\end{tabular}

\section{USE OF RESOURCES BY THOSE WITH DOWN'S SYNDROME}

The economic benefit of preventing the birth of handicapped people is the cost to the community of their care. In the case of an abortion followed by a successful normal pregnancy (replacement) this is the difference between the cost of caring for a handicapped person and that of caring for an average person. When there is no further pregnancy (no replacement) the cost is the total cost of caring for a handicapped person. In estimating these costs the use of resources by a nominal cohort of 100 people live-born with Down's syndrome was assessed. An estimate of the costs that would be incurred in the replacement situation is illustrated for representative years in table III. The derivation of these costs is indicated below; more detailed consideration is available elsewhere. ${ }^{11}$

Permanent care-We estimated the percentages of survivors in permanent care using projected Down's syndrome survival rates and the results of a recent west of Scotland survey. ${ }^{12}$ We considered that about a quarter of patients would be in permanent care by the age of 15 , half by the age of 25 , about three-quarters by the age of 35 , and all by the age of 45 . The additional cost of permanent care over residence at home is higher for children than for adults: the childhood costs include those of education. For a birth cohort of 100 the costs of permanent care were calculated to lie in the range $£ 3000-£ 16000$ a year (replacement and no replacement).

Education-In general children with Down's syndrome with IQs over $50(20 \%)$ attend special schools, while the remainder attend junior occupational or day care centres. ${ }^{13} 14$ For those continuing to live at home special education was estimated to cost $f 100-f 400$ more per child per year than normal schooling- $£ 10000-£ 25000$ more per year for a birth cohort of 100 (replacement and no replacement).

Lost maternal income-As their children get older an increasing proportion of women go out to work, but many of those with handicapped children stay at home to look after them. We assumed that labour force participation among mothers of children with Down's syndrome would be half that of average mothers with children of the same age. Hence, using published wage and employment data, ${ }^{15}$ we estimated that for a birth cohort of 100 six mothers would forgo total potential earnings of over $£ 6000$ a year when their children were young, and 11 to 15 mothers would forgo around $f 14000$ a year later on (replacement and no replacement).

Additional costs - Since no useful data are available on the additional services required to cope with the greater physical morbidity of those with Down's syndrome, we omitted the possible costs of such services from our calculations. The inability of most people with Down's syndrome to work, however, imposes a considerable economic burden on society. We assumed that only those with IQs over 50 could work, and then only with half the productivity of an average person. Using average lifetime earnings and consumption data, ${ }^{15}{ }^{16}$ we calculated that in the replacement situation for a birth cohort of 100 this would impose costs rising from about $£ 45000$ a year at age 16 to a maximum of about $£ 110000$ a year at age 25 .

Total costs-Estimates of total annual costs in each age group were obtained by adding the estimates under each heading for each year. In the replacement situation and for a birth cohort of 100 they were calculated to increase from under $£ 5000$ a year in infancy to over $£ 120000$ a year in middle life. A discount rate of $10 \%$ was applied to each year's total, and the discounted individual year totals added together to give the net present value of caring for a birth cohort of 100 people live-born with Down's syndrome. In the replacement situation this was $£ 415000$-that is, $£ 4150$ per person, and for no replacement $£ 10620$ per person. The lifetime consumption data available for calculation were not entirely appropriate to no replacement circumstances, however, and they probably exaggerated the net present value of costs.

Myelocele-The figure of $£ 3940$, estimated as the economic benefit from preventing the birth of an infant with myelocele, ${ }^{17}$ was used to calculate the economic benefits of preventing such births in the course of a Down's syndrome programme.

\section{PRENATAL DIAGNOSTIC PROGRAMME}

We calculated the costs of a programme to examine 550 women aged 40 and over each year; these women were estimated to be at risk of having $9 \cdot 1$ live-born infants with Down's syndrome. We assumed that $90 \%$ (495) of the women would attend antenatal clinic at the appropriate time for diagnosis (14th-18th week of gestation), that this would not entail extra antenatal clinic visits, that the chracteristics of attenders and non-attenders would be the same, and that, after genetic counselling, all attenders would accept amniocentesis (done on condition that affected pregnancies diagnosed would be terminated). All would receive ultrasonographic examination and amniocentesis. About 1\% (5) of amniotic fluid chromosome analyses would require repetition (calculation based on data supplied by Glasgow and West of Scotland Genetic Advisory Service), which would entail repeat attendance, ultrasonography, and amniocentesis. A diagnostic success

TABLE III-Costs of caring for cohort of 100 people live-born with Down's syndrome in the replacement situation

\begin{tabular}{|c|c|c|c|c|c|c|c|c|c|c|}
\hline \multirow[b]{2}{*}{ Age } & \multirow[b]{2}{*}{$\begin{array}{l}\text { No of } \\
\text { survivors }\end{array}$} & \multicolumn{2}{|c|}{ Permanent care } & \multirow[b]{2}{*}{$\begin{array}{l}\text { Cost of } \\
\text { education } \\
(£)\end{array}$} & \multicolumn{3}{|c|}{ Maternal income } & \multirow[b]{2}{*}{$\begin{array}{l}\text { Additional } \\
\text { costs } \\
(£)\end{array}$} & \multirow[b]{2}{*}{$\begin{array}{l}\text { Total } \\
(£)\end{array}$} & \multirow[b]{2}{*}{$\begin{array}{l}\text { Present value } \\
\text { (discounted } \\
\text { at } 10 \%) \\
(£)\end{array}$} \\
\hline & & $\begin{array}{l}\text { No }(\%) \text { in } \\
\text { care }\end{array}$ & $\underset{(£)}{\text { Cost }}$ & & $\begin{array}{l}\text { No of children } \\
\text { living at home }\end{array}$ & \begin{tabular}{|c|} 
No $(\%)$ of \\
mothers \\
unable to work
\end{tabular} & $\underset{(£)}{\text { Cost }}$ & & & \\
\hline $\begin{array}{l}1 \\
2 \\
3 \\
4 \\
5\end{array}$ & $\begin{array}{l}76 \\
73 \\
71 \\
69 \\
69\end{array}$ & $\begin{array}{l}4(5) \\
4(5) \\
4(5) \\
3(5) \\
5(7)\end{array}$ & $\begin{array}{l}4588 \\
4588 \\
4588 \\
3441 \\
5735\end{array}$ & 23560 & $\begin{array}{l}69 \\
67 \\
66 \\
64\end{array}$ & $\begin{array}{c}6(9) \\
6(9) \\
6(9) \\
12(19)\end{array}$ & $\begin{array}{r}6660 \\
6660 \\
6660 \\
13320\end{array}$ & & $\begin{array}{r}4588 \\
11248 \\
11248 \\
10101 \\
42615\end{array}$ & $\begin{array}{r}4171 \\
9295 \\
8451 \\
6899 \\
26460\end{array}$ \\
\hline 10 & 65 & $8(13)$ & 9176 & 20913 & 57 & $11(19)$ & 12210 & -4880 & 37419 & 14425 \\
\hline 16 & 59 & $14(23)$ & 3528 & & 44 & $12(27)$ & 13320 & 43939 & 60787 & 13227 \\
\hline 20 & 55 & $13(23)$ & 3276 & & 42 & $11(27)$ & 12210 & 61279 & 76765 & 9514 \\
\hline \multirow[t]{2}{*}{45} & 27 & $27(100)$ & 6804 & & & & & 89326 & 96130 & 1317 \\
\hline & & & & & & & & & Total & $£ 415000$ \\
\hline
\end{tabular}


rate of $99 \%$ would be expected. ${ }^{18}$ Thus $8 \cdot 1$ cases $(99 \%$ of $90 \%$ of $9 \cdot 1$ ) would be identified. In addition, 1.4 cases of anencephaly and 1.2 cases of myelocele ( 1 infant born alive) would be identified in this population. ${ }^{17}$

Costs-Costs to the Health Service and participants were calculated and are shown in table IV. Costs relating to time lost from work were derived from government data ${ }^{15}$ and those to medical genetics provision from local data (supplied by the Glasgow and West of Scotland Genetics Advisory Centre). Publicity, directed primarily at general practitioners, obstetricians, and the pregnant women, was estimated to cost the service $£ 2500$ a year with an additional $£ 2500$ in the first year. Attendance for genetic counselling would impose costs on women and husbands through lost working time and travelling ( $£ 2871$ a year) and on the service ( $£ 2094$ a year). We assumed that ultrasonographs in routine use would be available, but a small staff cost would be incurred ( $£ 372$ a year). Attendance for amniocentesis would impose costs on women ( $£ 2500$ a year) and on the service ( $£ 1448$ a year). Laboratory costs would all be borne by the service.

TABLE IV-Cost of prenatal diagnostic programme for Down's syndrome for women aged 40 and over in west of Scotland

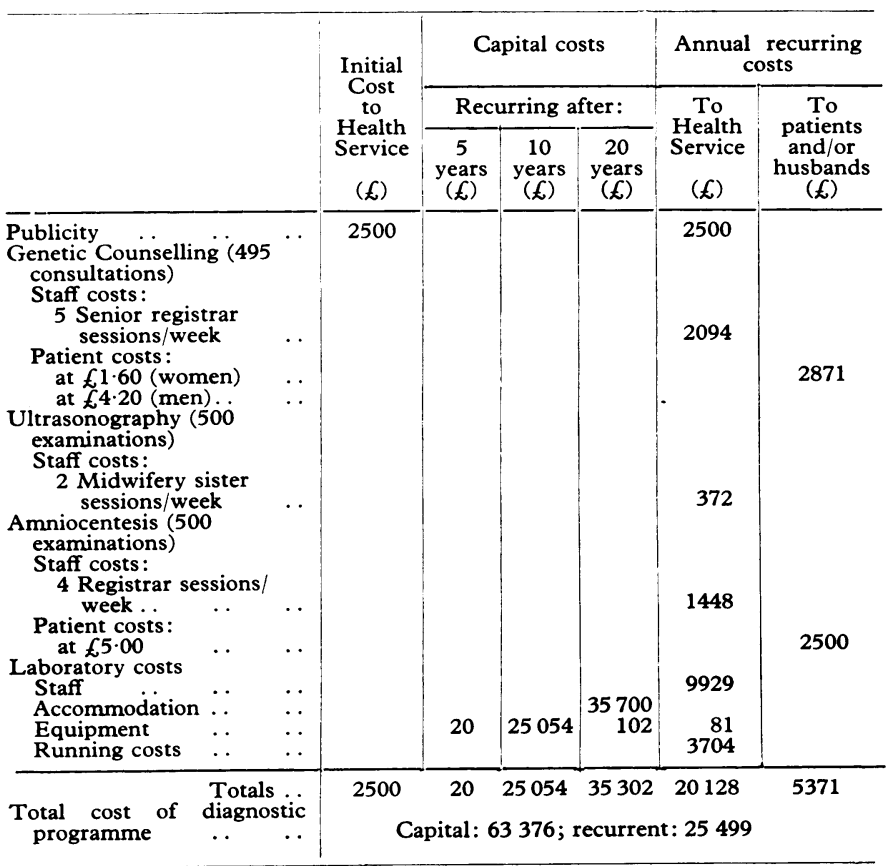

They were estimated to be (a) £35 700 for site and construction with at least 20 years' life, (b) $£ 9929$ a year for medical, scientific, technical, and records staff, (c) £25176 for equipment, which would need replacing from time to time, and $£ 81$ a year for its servicing, and $(d)$ $£ 3704$ a year for disposable materials, utilities, rates, and administration. The total cost of the first year of the 20 -year programme was given by adding the initial capital costs ( $£ 63376$ to the service) to the annual recurrent costs ( $£ 20128$ to the service and $£ 5371$ to the participants). The cost of each of the subsequent 19 years was the annual recurrent cost, plus the cost of equipment replacement if indicated-that is, plus $£ 20$ in the sixth year, $£ 25074$ in the 11th, and $£ 20$ in the 16 th. Accommodation and certain equipment costs (total $£ 35802$ ) would not recur within a 20-year programme. A discount rate of $10 \%$ was applied to each year's total, and the discounted individual year totals added together to give the net present value of total costs of establishing and maintaining a 20-year diagnostic programme- -311855.

\section{TOTAL BENEFITS AND COSTS}

The programme described, costing $£ 311855$, would prevent the births of 8.1 children with Down's syndrome each year and 1.0 with myelocele, and thus in the replacement situation produce an annual economic benefit of $(8.1 \times £ 4150)+(1.0 \times £ 3940)=£ 37555$. A discount rate was applied to this sum for each of the 20 years of the programme and the discounted individual year totals added together to give a net present value for the total economic benefits of the programme, amounting to $£ 351699$. The corresponding value of economic benefits from preventing Down's syndrome alone in the no replacement situation would be $£ 805$ 587. In each case therefore the value of economic benefits would exceed that of costs.

Programme for women aged 35 and over-Corresponding calculations were made, and the findings were: costs, $£ 1193312$; economic benefits, $£ 752579$ (replacement situation) and $£ 1496358$ (no replacement situation).

\section{Discussion}

Economic benefits were divided by costs to give benefit:cost ratios. For women aged 40 and over these were: $1 \cdot 13$ (replacement) and 2.58 (no replacement). If, after genetic counselling, only half accepted amniocentesis and possible termination the benefit:cost ratios would be reduced by $25 \%$ (to 0.84 in the replacement situation, for example). But the no replacement situation would probably apply to almost all women of this age, so the overall benefit :cost ratio would considerably exceed unity, even were participation reduced so considerably and even after allowing for the probable exaggeration of the no replacement ratio caused by the inappropraite nature of the available lifetime consumption data. This suggests that there would be net economic benefits from providing a prenatal diagnostic programme for this age group. This view is reinforced by new evidence from several centres, including Glasgow, that the birth prevalence of Down's syndrome among women over 40 may be up to twice that reported by Lindsjo.. ${ }^{18}$

For the complete over-35 age group the benefit:cost ratios were: 0.63 (replacement) and 1.25 (no replacement). If after genetic counselling only half accepted amniocentesis and possible termination the benefit:cost ratios would again be reduced by about $25 \%$ (to 0.48 in the replacement situation, for example). But were this $50 \%$ participation confined to those under 40 , perhaps as a result of their acting on self-recognition of their low risk of fetal abnormality, the benefit :cost ratios would be slightly higher than 0.63 and 1.25 . The availability and inclusion of such resource use data as those relating to morbidity from physical illness or to social services would probably also raise the benefit: cost ratios; incorporation of better lifetime consumption data in the no replacement situation, however, would probably have the opposite effect. Furthermore, although no replacement could be expected to apply to most of the age group, the bias in its favour would presumably be less pronounced than among the over $40 \mathrm{~s}$. With all these factors taken into account, the costs of a prenatal diagnostic programme for the complete over- 35 age group would probably be about equal to the net economic benefits, so that, on economic grounds, this programme too could probably be justified. Its development might follow initial provision to the over 40s, from which the collection of appropriate epidemiological and resource use data would provide for more accurate economic calculation for the younger age group.

It has been suggested that it would be economically justifiable to extend prenatal diagnosis of Down's syndrome to women under $35 .{ }^{19}$ The data and calculations presented here make this seem unlikely. Such a decision would therefore have to rest on other considerations of the priorities for health expenditure. In any case the view that amniocentesis should be offered to women whose risk of diagnosable severe fetal abnormality is remote ${ }^{19}$ needs critical re-examination.

Our conclusions rest on the assumption that those responsible for health planning embrace the cost-benefit analysis approach -perceiving their responsibilities beyond the narrow framework of health services accountability, and accepting a long-term economic perspective. The findings also re-emphasise that society's response to the problem of Down's syndrome cannot rest solely on consideration of economic costs and benefits. If Down's syndrome is socially unacceptable provision of a programme to reduce its birth prevalence by scarcely a third would be an inadequate response. Conversely, failure to implement a programme for all maternal age groups would imply that there 
were other, perhaps more appropriate, responses to the problem of Down's syndrome. Since this would call into question any programme directed at identification and termination of affected pregnancies, it would be logical to resolve this dilemma before any programme was started.

The authors thank members of staff of the Glasgow and West of Scotland Genetic Advisory Centre for providing detailed information about their work, Mr R G Milne for several original ideas, Dr F A Boddy, Professor M A Ferguson-Smith, and Professor G T Stewart for giving helpful advice, and Mrs F Sinclair for secretarial help.

\section{References}

${ }^{1}$ Drillien, C M, Jameson, S, and Wilkinson, E M, Archives of Disease in Childhood, 1966, 41, 528

2 Mental Handicap, 17 . London, Office of Health Economics, 1973.

3 Economic Progress Report. London, Information Division of Treasury, 1974

4 Lindsjö, A, Acta Paediatrica Scandinavica, 1974, 63, 571.

5 General Register Office, Scotland, Report of Registrar General for Scotland, Edinburgh, HMSO, 1973.
5 General Register Office, Scotland, Report of Registrar General for Scotland, Edinburgh, HMSO, 1973.

7 Penrose, L S, and Smith, G F, Down's Anomaly, p 152. London, Churchill, 1966.

${ }^{8}$ Collmann, R D, and Stoller, A, Fournal of Mental Deficiency Research, $1963,7,53,60$.

${ }^{9}$ Fabia, J, and Drolette, M, Fournal of Mental Deficiency Research, 1970, $14,235$.

${ }_{10}$ Ross, H S, Innes, G, and Kidd, C, Scottish Medical fournal, 1967, 12, 260

11 Carter, F A, and Hagard, S, Calculating the Costs of Down's Syndrome. University of Strathclyde Health Services Operational Research Unit. Mimeograph, 1975

12 Milne, R G, Institutional Provision for Mongolism and Spina Bifida in Scotland, submitted for publication.

13 McKeown, T, and Lowe, C R, An Introduction to Social Medicine, p 317. 2nd ed. Oxford, Blackwell, 1974.

14 Scottish Education Department, Degrees of Mental Handicap. Edinburgh, HMSO, 1961.

15 Central Statistical Office, Social Trends, London, HMSO, 1973.

16 Central Statistical Office, Annual Abstract of Statistics. London, HMSO, 1973.

17 Hagard, S, Carter, F A, and Milne, R G, British fournal of Preventive and Social Medicine, in press.

18 Ferguson-Smith, M A, et al, Health Bulletin, in press.

19 Stein, Z, Susser, M, and Guterman, A V, Lancet, 1973, 1, 305.

\title{
Problems of Childhood
}

\section{Wheezing children}

\author{
J K SARSFIELD
}

British Medical fournal, 1976, 1, 756-759

The wheezing child is a common clinical problem. Asthma is by far the commonest cause of wheezing, but other conditions must be considered, especially in the young child. These include respiratory tract infection, expecially viral bronchiolitis, inhalation of a foreign body, cystic fibrosis, primary tuberculosis, and congenital anomalies. Clinical and radiological examination will usually identify these conditions.

The role of infection in wheezing in the young child is not clear. Acute bronchitis with airways obstruction may produce a wheeze with associated respiratory distress, fever, leucocytosis, and general malaise. If these attacks recur terms such as "wheezy bronchitis," "asthmatic bronchitis," and "pseudoasthma" are applied. Antibiotics are often prescribed but with doubtful benefit. Viral infection may be responsible for some attacks, but several studies have shown that viruses can be isolated from only about a third of patients and their role in the pathogenesis is uncertain. Williams and $\mathrm{McNicol}^{1}$ made a valuable contribution to our understanding of this group of young wheezing children who have apparent preceding infection. After a prospective long-term epidemiological study they concluded that they could not separate recurrent "wheezy bronchitis" from asthma. Their evidence suggests that both conditions exhibit a common basic asthmatic disorder, but the

Department of Paediatrics and Child Health, University of Leeds, Leeds LS14 3ET

J K SARSFIELD, MD, MRCP, lecturer in paediatrics spectrum of severity varies greatly from a few mild early attacks that abate to established severe asthma persisting into adult life.

\section{Asthma}

In the absence of any widely accepted definition of asthma it seems reasonable to consider it, simply, as a constitutional disorder characterised by hyper-reactivity of the airways. Various factors may provoke this reactive state and lead to paroxysmal attacks of airways obstruction producing respiratory distress and wheezing. The basic constitutional disorder is probably biochemical and almost certainly has a genetic basis, but the precise mode of inheritance is unknown. This familial tendency, however, may help the doctor towards an earlier diagnosis and hence more appropriate management.

An understanding of the known basic mechanisms concerned in the cause of asthma is essential to proper assessment and management.

\section{Allergy}

Most asthmatic children have demonstrable allergies. The incidence of hay fever, eczema, and urticaria is much higher in these children and their families than in non-asthmatics. The fact that an acute attack of asthma may be a manifestation of an immunological hypersensitivity reaction to an external provoking antigen (allergen) has been recognised for many years. Recent advances have established that antibodies belonging to a newly recognised immunoglobulin class, IgE, are concerned. These antibodies are firmly attached to mast cells in the bronchial mucosa, and on exposure to an offending allergen the antibodyantigen reaction causes the release of vasoactive amines from 